\title{
SHORT TERM CHANGE DETECTION IN TUNDRA VEGETATION NEAR UMIUJAQ, SUBARCTIC QUEBEC, CANADA
}

\author{
L. Provencher-Nolet ${ }^{1,3}$, M. Bernier ${ }^{1,3}$, E. Lévesque $e^{2,3}$ \\ ${ }^{1}$ Institut National de la Recherche Scientifique, Québec, QC, Canada \\ ${ }^{2}$ UQTR, Trois-Rivières, QC, Canada \\ ${ }^{3}$ Centre for Northern Studies, Québec, QC, Canada
}

\begin{abstract}
Local vegetation changes since the last 20 years are being investigated at the transition zone between the subarctic and the arctic region in Nunavik (Quebec, Canada). By using high resolution aerial photographs acquired at the end of summer 1994 and 2010 and image processing techniques, we established the dominant vegetation changes and created a «from-to » vegetation map. Results show a significant increase in shrub dominated cover and a loss of lichen dominated zones. Number and area of ponds have also diminished over time. Moreover, according to the change detection analysis, all major vegetation classes had the largest shift in favour of the shrub class. Thus, the final change map illustrates the general shrubification ongoing in the region and pinpoints permafrost degradation zones as principal areas affected by the expansion of shrubs.
\end{abstract}

Index Terms - High-resolution imaging, image classification, change detection, vegetation, arctic

\section{INTRODUCTION}

Since the mid-1990's, station and experimental measurements of climate variables indicate a strong climatic change occurring in the Nunavik (Northern Quebec Province), Canada. Recently, consequences on vegetation density and patterns have been reported either by local Inuit knowledge [1] and scientific investigations. Field studies and analysis of aerial photographs and satellite images show that poleward migration of the boreal forest [2,3] and the expansion of shrub tundra [4,5] are already ongoing in subarctic Quebec. Because field work in the north is very expensive and time consuming, the processing of high resolution imagery represents a fast and powerful tool to monitor these local changes. Moreover, with the improvements in image resolution, semi-automatic techniques to classify landscape on a local scale, such as object-based classifications, are becoming commonly used, as they are better adapted to deal with the complexity of the scene than the traditional pixel-oriented analysis [6].

In this perspective, our study had the objective to establish the local change in the vegetation since the last 20 years by using $<1 \mathrm{~m}$ spatial resolution photographs and object-based classification. From the processing of these photos, our goal was to identify, quantify and spatialize the vegetation shifts ongoing in Tasiapik valley.

\section{METHODOLOGY}

\subsection{Study area}

The study field is located in Tasiapik valley, few kilometres east Umiujaq inuit village $\left(56.55^{\circ} \mathrm{N}, 76.55^{\circ} \mathrm{W}\right)$ on the eastern shore of the Hudson Bay (Quebec, Canada). The area is situated in the discontinuous permafrost zone at the forest-tundra ecotone (fig. 1), and thus is expected to be particularly sensitive to climate driven vegetation changes. The valley is surrounded by cuestas, which form a natural barrier for harsh winter winds and allow tree forested areas (mainly Picea mariana). Vegetation in the valley is heterogeneous: higher topographic zones dominated by lichen, large areas dominated by erected shrubs (birch, willow and alder in wetter zones), some permafrost mounds in degradation associated with lichen-shrub vegetation and few herbaceous vegetation zones found in wet areas.

Climate data from Kuujjuarapik station $\left(55^{\circ} 28^{\prime} \mathrm{N}\right)$, located $160 \mathrm{~km}$ south Umiujaq, yields a mean annual air temperature of $-4.2^{\circ} \mathrm{C}$ from 1958 to 1989 and a mean air temperature of $-3.0^{\circ} \mathrm{C}$ from 1990 to 2013 [7]. Annual precipitation is $550 \mathrm{~m}$ and more than the third falls as snow [8].

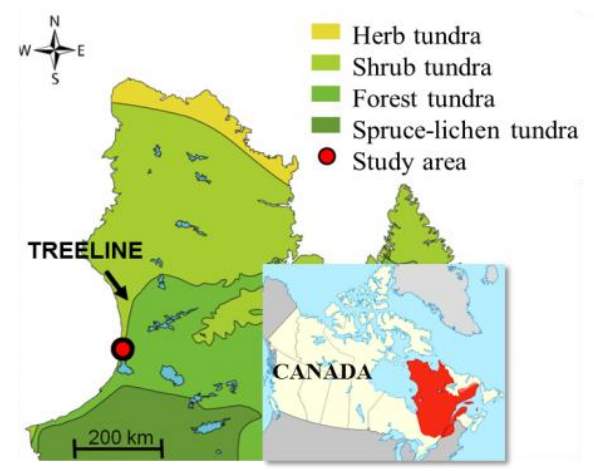

Fig. 1 Study area situated at the treeline, Nunavik, Quebec, Canada (figure adapted from [9]). 


\subsection{Data processing}

To characterize the vegetation, we used two airborne color photographs series $(15 \mathrm{~cm}$ spatial resolution) of Tasiapik Valley acquired by the Quebec Government in August 1994 and 2010, both respectively analogous and numerical (fig. 2). Since the 2010 photos were already georeferenced, the 1994 photos were geometrically corrected and rigorously matched to the 2010 digital photo mosaic. The spatial lag between the two mosaics is $1,78 \mathrm{~m}$ (XRMS) and $1,70 \mathrm{~m}$ (YRMS). For faster image processing, both mosaics were resampled at a resolution of $80 \mathrm{~cm}$.
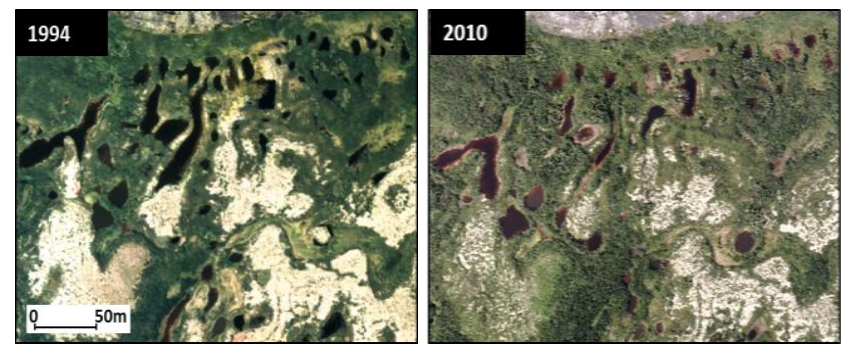

Fig. 2 Subscene of the photo mosaics (1994 and 2010) taken both in the lower Valley. White areas- which are mainly lichen - are far more present in 1994. In 2010, these areas seem to have been partly covered by the expansion of shrubs.

In order to assess the vegetation shift magnitude over time, we first mapped the vegetation through an objectbased classification method well adapted to the high resolution of the images [10]. This method consists in segmenting the image into meaningful objects, i.e. into groups of adjacent pixels that share similar characteristics [6]. The generated segments are then classified with the nearest neighbor algorithm based on chosen information layers (spectral and textural bands, digital elevation model, etc.). Image segmentation and classification were achieved using Definiens eCognition 8.7.2 software.

Validation of the classifications was made with more than 600 test sites taken randomly on the image. The resulting error matrix allows the accuracy of the classifications to be calculated [11]. As control plots were indispensable for photointerpretation and for the selection of training and test sites, in situ data of vegetation covers was collected over 80 plots of $2 \mathrm{~m}$ by $2 \mathrm{~m}$ during a five weeks campaign in summer 2012. Thus, vegetation thematic classes were chosen based on field investigations and on separability tests made on both images. Final classes were established according to the dominated vegetation cover $(+50 \%$ covering): lichen zones, herbaceous vegetation, shrub lands, spruce tundra, sparsely vegetated rock (outcrop and scree) and water.

Finally, the two validated thematic maps were superimposed and a change matrix was computed in order to identify and quantify land cover changes [12]. From that matrix, we produced a "from-to" vegetation map to spatialize the nature of change.

\section{RESULTS}

Final vegetation maps have a global accuracy of $85 \%$ and $84 \%$ for 1994 and 2010 respectively [12]. Results can be appreciated through a quantitative comparison of the absolute areas occupied by each land cover classes for both years (fig. 4). Quantitative results show that the only class that had an increase of area is the shrub class, with a gain of more than 60 ha from 1994 to 2010, meaning that shrub has grown by $24 \%$ of its original area. In contrast, lichen had the most important area loss of 43 ha. Herb dominated and rock areas have also diminished whereas spruce tundra is quite stable over time. Lakes and ponds had shrunk in terms of area and number (relative loss of $22 \%$ ), probably caused by paludification processes. By comparing visually the two maps [12], there is a general decrease in lichen in favor of green areas (shrub lands), especially in the lower part of the valley. Furthermore, a substantial loss of herb dominated land can be seen in the upper valley in the vicinity of the road. This could have been caused by the recent road excavation which may have had a local draining effect.

Tab. 1 Area occupied by each land cover classes in 1994 and 2010.Total areas for both years are not equal because of the omission of the road class, which has expanded over time.

\begin{tabular}{lcccc}
\hline \multicolumn{1}{c}{ Vegetation classes } & \multicolumn{2}{c}{$\mathbf{1 9 9 4}$} & \multicolumn{2}{c}{$\mathbf{2 0 1 0}$} \\
& $h a$ & $\%$ & $h a$ & $\%$ \\
\hline Lichen dominated & 123.7 & 23.4 & 80.8 & 15.5 \\
Shrub dominated & 252.1 & 47.7 & 313.0 & 59.9 \\
Spruce dominated & 87.2 & 16.5 & 86.6 & 16.6 \\
Herb dominated & 28.8 & 5.5 & 18.3 & 3.5 \\
Ponds & 6.5 & 1.2 & 5.0 & 0.9 \\
Rock/scree & 27.1 & 5.1 & 16.2 & 3.1 \\
Unclassified & 2.7 & 0.5 & 2.9 & 0.6 \\
\hline TOTAL & 528.2 & 100 & 522.8 & 100 \\
\hline
\end{tabular}

The superimposition of both classifications shows that all vegetation classes of 1994 have predominantly turned to shrub land in 2010 , accounting for $18 \%$ of the total area. Among these changes, the shift from lichen to shrub dominated tundra is the most important. Thus, the resulting "from-to" vegetation map (fig. 5) shows well the landscape shrubification over time.

\section{CONCLUSION}

This study's main objective was to establish the local change in vegetation in the Umiujaq area, Nunavik, Canada. The processing of $<1 \mathrm{~m}$ spatial resolution photographs showed that shrub land had an absolute increase in area of 60 ha 

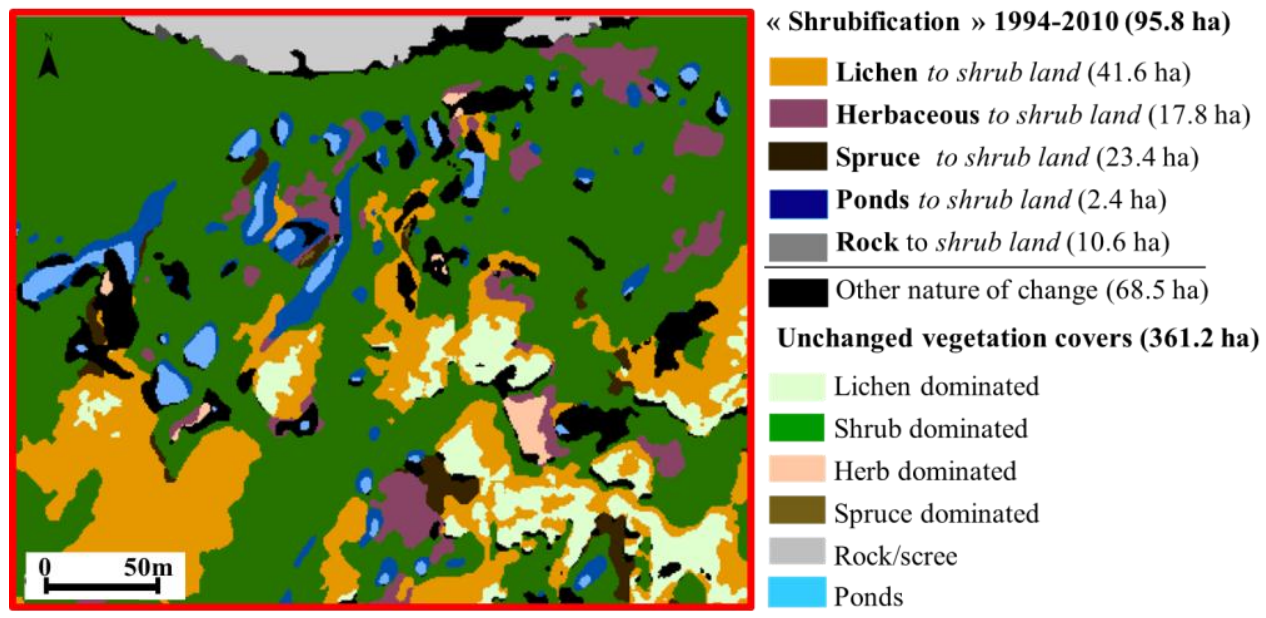

Fig. 3 Subscene (same of fig. 2) of the final change detection map [12] showing the shift from the 1994 land cover classes to shrub lands (2010). Areas in parenthesis refer to the entire change detection map (total area: 525.5 ha).

from 1994 to 2010 and lichen had a substantial decrease of 43 ha. Moreover, change detection analysis has shown that the major change affecting all land cover classes in 1994 was a shift to the shrub class, accounting for $18 \%$ of the total studied area. Our results support that object-based classification method coupled with change detection techniques is well suited for quantitative investigations of local vegetation changes in subarctic environment. The final change detection map will soon be available via NordicanaD, the Centre for Northern Studies' online database.

\section{REFERENCES}

[1] J. Gérin-Lajoie, A. Cuerrier and E. Lévesque, "Inuit perception of climate change and its effect on vegetation and berry species in three communities of Nunavik, Quebec", In prep for Human Ecology.

[2] I. Gamache and S. Payette, "Latitudinal response of subarctic tree lines to recent climate change in eastern Canada". Journal of Biogeography, vol. 32, no. 5, pp. 849862, 2005.

[3] I. Gamache and S. Payette, "Height growth response of tree line black spruce to recent climate warming across the forest-tundra eastern Canada", Journal of Ecology, vol. 92, pp. 835-845, May 2004.

[4] P. Ropars and S. Boudreau, "Shrub expansion at the forest-tundra ecotone: spatial heterogeneity linked to local topography", Environmental Research Letters, vol. 7, pp. 29, January 2012.

[5] B. Tremblay, E. Lévesque and S. Boudreau, "Recent expansion of erect shrubs in the Low Arctic : evidence from
Eastern Nunavik", Environmental Reearch Letters, vol. 7, pp. 1-11, July 2012.

[6] T. Blaschke, "Object-based image analysis for remote sensing", ISPR Journal of Photogrammetry and Remote Sensing, vol. 65, no.1, pp. 2-16, January 2010.

[7] Environment Canada, Climate database [Online] : http://climate.weather.gc.ca/

[8] E. Ménard, M. Allard and Y. Michaud, "Monitoring of ground surface temperature in various biophysical microenvironments near Umiujaq, eastern Hudson bay, Canada.", PERMAFROST - Seventh International Conference, YellowKnife, Canada, pp.723-729, June 1998.

[9] A. Truchon-Savard and S. Payette, "Black spruce colonization of forest-tundra snow patches of eastern Canada". in 42nd International Arctic workshop, Winter Park, Colorado, March 2012.

[10] M. Dissanska, B. Monique and S. Payette, "Objectbased classification of very high resolution panchromatic images for evaluating recent change in the structure of patterned peatland", Canadian Journal of Remote Sensing, Vol 35, no. 2, pp.189-215, June 2009.

[11] G.R. Congalton, "A review of assessing the accuracy of classification of remotely sensed data", Remote Sensing of Environment, vol. 37, pp.35-46, 1991.

[12] L. Provencher-Nolet, "Détection de changements à court terme de la toundra arbustive à partir de photographies aériennes, région d'Umiujaq, Nunavik (Québec, Canada) ", Master thesis, University INRS, Quebec, Canada, 162 p., 2014. 